\title{
A NEW MODEL FOR TESTING GREEN CONSUMER BEHAVIOUR
}

\begin{abstract}
Several models of green consumer behaviour have sought to explain the relationship between green attitudes and the behaviours of individuals related to green consumption, based on traditional theories. Nevertheless, it has been difficult to develop an optimum or even a consensual model to predict green consumer behaviour. This paper seeks to examine the links between a set of constructs, in order to propose a model for green consumer behaviour based on a different set of antecedents of buying behaviour: prosocial attitude, the value placed on green and green communication. A survey, taking the form of a self-administered questionnaire, was developed to gather data; Structural Equation Modelling (SEM) was used for the analysis. The results show that general prosocial attitudes have a direct influence on green consumption values, and that green values positively influence green buying behaviour and receptivity to green advertising. However, green advertising presents only a weak influence on green buying behaviour. The relationship between these concepts is important to consider when developing green marketing campaigns and communication to influence further green behaviour.
\end{abstract}

Key words: Green behaviour, Prosocial, Green communication, Buying behaviour 


\section{Introduction}

In the context of a need for sustainable development, research that seeks to understand the factors that influence environmentally friendly behaviours has increased rapidly in the last ten years, with particular attention focused on green purchasing behaviour. Although there have been advances in teasing out the relationships between concern for sustainability and environmentally friendly consumption, several questions remain unanswered, for example, why is concern for the environment not always translated into effective purchasing behaviours; why are intentions not converted into environmentally friendly actions/activities? In a context where over-consumption has environmental impacts that threaten the planet, and increasing the purchase of environmentally friendly products is seen as an important component of reducing environmental impact (Liobikiene and Bernatoniene, 2017), understanding the green consumer continues to be a growing area of research and an important focus for marketing. Here, environmental impacts should be understood as "the influence of human-dominated systems of production and consumption on the Earth system as a result of restructured biophysical resources" (Liu et al. 2016, p.14).

Maniatis (2016) suggests that research shows a multiplicity of indicators that influence consumers' knowledge and awareness, green consciousness, and commitment towards green products (i.e. products with a reduced impact on the environment). However, what is missing is a lack of structural constructs that detail how these indicators come into play and interact during the decision-making process (Maniatis, 2016). He et al. (2016) also reinforce that wellgrounded theoretical frameworks for consumers' green or non-green consumption are difficult to find. The authors suggest Consumer Choice Theory shows how economic influences explain why consumers do or do not engage in green behaviours. Consumer choices depend on the budget available and their preferences, with the under-lying principle that consumers are completely rational. In turn, the Theory of Consumption Values (Sheth et al., 1991) has three underlying principles: consumption behaviour is a function of multiple consumption values; the influence of each consumption value in a given situation varies considerably; and the values are independent of each other. This theory explains consumer choice as a function of multiple consumption values along several dimensions (e.g., quality, appeal, emotions, environmental impact, etc.) (Rahnama and Rajabpour, 2017). 
Additionally, several models of green consumer behaviour have sought to explain the attitudes and behaviours of individuals, building on the Theory of Reasoned Action (TRA) and the Theory of Planned Behaviour (TPB). Fishbein and Ajzen (1975) developed the TRA to explain behavioural intentions. The theory is very effective in explaining and developing understanding of the psychological and cognitive processes involved in consumers' contextual decision-making, as well as the extent to which consumers are willing to buy green products or adopt green practices (Paul et al., 2016). In turn, TPB links an individual's beliefs and behaviours, adding to TRA by incorporating the concept of perceived behaviour control (Ajzen, 1991), leading to a better result in the purchase intention model's predictability for green products (Paul et al., 2016). Nevertheless, despite advances, it has been difficult to develop an optimum and/or a consensual model that would serve to predict green consumer behaviour. Overall, the literature suggests that there is a gap between consumers' proenvironmental attitudes and sustainable consumption behaviours, with a suggestion that further research is needed to develop understanding of the factors that influence behaviour and the relationship between variables (Biswas, 2017; He at al., 2016).

In short, the theories used to explain green behaviour have largely focused on economic influences (for example, Consumer Choice Theory), on consumption values influences, such as quality, appeal, emotions, among other factors (for example, Theory of Consumption Values), on psychological and cognitive influences (Theory of Reasoned Action), or on beliefs influences (Theory of Planned Behaviour). In order to help fully explain green behaviour, models that integrate more social concerns and attitudes, as well as external influences, are needed

In response to the call for further research, this paper seeks to consider the influence of the social by including prosocial attitudes (the lasting dispositional tendency for an individual to think about the rights and well-being of others, to feel empathy and worry for others). It also includes the value placed on green - the tendency to explore the value of environmental protection through purchases and consumption behaviours), and green communication (attention given to or feelings in relation to green advertising) on green behaviour. Although prosocial attitudes relate to an individual's disposition, they also reflect individuals' attitudes towards society and others. Therefore, pro-social attitudes might serve as an important factor to incorporate in a model that seeks to explain green behaviour. Similarly, green 
communication might be an important external influence and is a factor that has not featured extensively in other models.

The paper is structures as follows: first, the literature review is presented outlining the concepts used and the model developed in this study; second, methods and data collection will be explained. Third, analysis of results and conclusions are provided.

\section{Literature Review}

\subsection{Green Consumer Behaviour - an overview}

According to Straughan and Roberts (1999), marketing research related to environmental issues has advanced through different stages from the 1960s, when the ecology movement, focused attention on pollution and energy conservation. Since then, concerns about environmental issues have increased with each decade. Today, sustainability is a well-known topic and has become a critical concern, not just for governments and the public in general but also for marketers; addressing the green market (as a rapidly increasing market segment) is now seen as a source of competitive advantage and added value. The perception that the planet is reaching very high levels of pollution and degradation has contributed to the emergence and growth of the environmental protection "movement" (Lee, 2009) and in parallel, to the rapid growth of a new market segment -green consumers, who are likely to be engaged in green behaviour (Paço and Raposo, 2010).

The adoption of green behaviour is a central aspect of achieving sustainability. Green behaviour is generally associated with green consumption. It involves using goods that do not cause pollution and damage to the natural environment and acting with a sense of social consciousness and social responsibility. It also embraces being concerned about the sustainability of resources for future generations; avoiding excessive consumption by choosing recyclable products with high durability, high quality and ecological labels and; reducing consumption of resources and energy (He et al., 2016; Huttunen and Autio, 2010; Shi, 2002; Tripathi and Singh, 2016). However, despite substantial efforts, the 'green movement' has not been as successful as one might expect; research reveals limited impact in a number of areas. For instance, regarding ecolabels, except for a minority of product groups, evidence shows that the market share of eco-labelled products is relatively low as a fraction of 
the total market (Rex and Baumann, 2007). This is an opportunity cost, given that labelling is effective in fostering positive attitudes in consumers (Cerri et al, 2018). In relation to energy, a significant part of society is unaware of the benefits of energy efficiency and energy preservation (although females are much more willing to engage in energy saving behaviour as well as the young adult, as noted by Kuo et al., 2018). Similarly, in relation to recycling, Herbes et al. (2018) consider that consumers focus mainly on end-of-life attributes of packaging and are less concerned with renewable origins, evidencing that there is some misunderstanding of renewable energy sources (e.g. green gas).

In seeking to understand green behaviour, the concept of environmental concern or ecological concern has featured in a number of studies, for example Schlegelmilch et al. (1996), Lee (2008) and Paço et al. (2013). In the main, these studies have focused on research into what constitutes the construct "ecological concern", the effects of predictor variables (demographics, personality, knowledge, value orientation, etc.) and the relationship between environmental concern and behavioural patterns (Paul et al., 2015). Unfortunately, the research evidence suggests that even when consumers express real concerns for the environment, such attitudes will not always influence their purchasing behaviour. In some cases, there is evidence to suggest that individuals who are more concerned about environmental issues will have a disposition to buy more green products (e.g. Chan, 1996). Other studies (e.g. Laroche et al., 2002) report that many consumers will only act according to their environmental concerns, if that action does not involve personal expense such as changes and /or significant sacrifices in lifestyles. Further, some studies show a weak attitudebehaviour relationship (e.g. Maloney and Ward, 1973; Hini et al., 1995), which is in sharp contrast to other research (e.g. Loundsbury and Tournatsky, 1977) where a strong connexion between the variables is demonstrated. It is important to note however that for the most part, studies attempting to explain the gap between attitudes and buying behaviour have been rooted in the field of consumer psychology (Rex and Baumann, 2006).

As consumers become aware of how their consumption influences the environment, there is some evidence to suggest that they do try to change their attitudes and behaviours for the benefit of future generations (Urien and Kilbourne, 2011). Although satisfying personal needs seems to remain a crucial factor, environmental conservation and social consciousness are more recently becoming a primary concern (Paul et al., 2016). In relation to social 
consciousness, 'prosocial attitude' as a concept, merits consideration in relation to green consumption.

\subsection{Prosocial Behaviour}

Prosocial behaviour is a cooperative act that describes actions which will protect or enhance the well-being of others (Weinstein and Ryan, 2010), and includes interventions of great utility, such as in the case of activities aiming for environmental preservation.

Zabkar and Hosta (2013) suggest that prosocial status serves as a moderating variable, where actual environmentally friendly consumption is likely to increase as prosocial status perceptions are increased. Welte and Anastasio (2010) add that the social context in which an individual finds him or herself can limit, support, or even disrupt individual goal seeking behaviour, by imposing certain rules and values, which then become attached to certain decisions. The effect is to persuade individuals to behave in a certain way. In this way, social context, and a belief about how other people perceive certain behaviour, can be an important driver of environmentally conscious behaviour. Prosocial status perceptions of environmentally friendly consumer behaviour contribute towards reducing the gap between the predisposition to act in an environmentally friendly way and actually behaving in an effective environmentally friendly way (Zabkar and Hosta's, 2013). In essence, if the individual is part of a social group and members of that group take environmental actions then the individual is more likely to behave in a similar way.

Usually, people with a higher propensity to perform prosocial behaviours have a greater tendency for a prosocial personality, which is characterised by the desire to perform altruistically motivated behaviours (Steele et al., 2008). Steele et al. (2008) state that altruistic and empathy traits of an individual are evident and developed in childhood and are personality traits. Further, positive emotions trigger prosocial behaviours and lead to more cooperative conduct (Snippe et al., 2018). Nevertheless, cooperation is not always without conflict and requires a certain amount of self-control: it involves a balance between the desire to cooperate and the comfort of being more selfish. If helping others comes with personal cost, individuals will experience a tension between competing prosocial concerns and pro-self desires. To act on their prosocial concerns, individuals must exert self-control to overcome the influence of these pro-self desires. Thus, any process that reduces the capacity or motivation of the individual for self-control can lead to reduced cooperation. In this way, non- 
cooperation may not be related to a lack of concern for others, but to an inability to act upon human nature (Osgood and Muraven, 2015).

According to Osgood and Muraven's (2015) research, prosocial affect and cognition are insufficient to cause prosocial behaviours and such affects and perceptions may not be consistent with their corresponding behaviours. The authors suggest that efforts aimed at increasing prosocial behaviours (e.g. green behaviours, volunteering, donation, etc.) should focus not only on promoting prosocial attitudes but also on reducing the perceived cost and/or inconvenience to the self.

\subsection{Green consumption values}

Haws et al. (2014, p. 337) introduced the concept of green consumption values defining it as "the tendency to explore the value of environmental protection through one's purchases and consumption behaviours". They explored and developed a method to understand differences across consumers who do and who do not value preserving and conserving the environment, as part of their consumption behaviour. The construct of green consumption values can be understood as the tendency to express the value of environmental protection through one's purchases and consumption behaviours. Thus, consumers with stronger green consumption values are generally more oriented towards protecting resources and buying in a responsible way. Further, the authors validated the predictive ability of the construct on consumer decisions regarding environmentally relevant purchases, by demonstrating more favourable attribute evaluations, which are consistent with motivated reasoning processes in more traditional consumer decisions not related to the pro-social context of environmental decisions.

Regarding the issue of "conserving", it should be noted that previous research suggests that conserving behaviour may be achieved throughout purchase and non-purchase activities. Pickett et al. (1995), for example, in order to study the implications of the conserving consumer for public policy, developed a scale focused on conservation activity comprising a broad range of items: dispositional activity, recycling of non-durable goods and their packaging, preservation of resources and attitude towards packaging. The individuals less involved in such activities seemed to be, less affected by pollution problems and less concerned with social problems. In addition, Haws et al. (2014), in relation to the desire of 
consumers with strong green consumption values to use society's environmental resources, prudently suggest that green consumers also value conservation of their personal resources.

This concept of green consumption values can be an alternative to the "socially conscious consumer" concept since its general notion is multidimensional. Thus, studies of socially conscious consumption have often led to long and complex measures aimed to capture the full scope of the constructs involved (e.g. Antil, 1984).

Green consumption values are highly related to the adequate use of collective environmental resources and personal assets. That is, both the tendency to use financial resources prudently (frugality, value and price consciousness, spending self-control) and the tendency to use physical resources consciously (frugality, use innovativeness, product retention tendency) are positively correlated with green consumption values (Haws et al., 2014). Accordingly, Sheth et al. (2011) found that greener consumers not only have concern for environmental resources but also for personal resources, indicating the need to focus on the personal and economic well-being of individuals.

Frugality can be translated into the careful acquisition and consumption of goods, covering the attentive use of both financial and physical resources (Lastovicka et al., 1999). Haws et al. (2014) associate this frugality with green values because of the importance a frugal consumer places on the careful use of financial resources in obtaining goods, and concern for physical assets during consumption. The analysis of consumer spending self-control is also relevant because we expected that greener consumers are conscious and controlled in their spending decision-making (Haws et al., 2012). Price consciousness can also be considered a measure of value consciousness because of the focus on careful use of financial resources (Lichtenstein et al., 1993).

The conservative use of personal physical resources relates to the tendency to retain or renounce possessions and be more innovative in the use and reuse of products. Haws et al. (2014) defend that green consumers will be reluctant to give up their physical possessions because they will seek to extract all value from goods before discarding them. Additionally, green consumers will be more likely to be innovative users of existing physical resources, looking for the creative reuse and find multiple uses for their products. 
Understanding the impact of green consumption values on consumption behaviour is critical, as an increasing number of companies focus on products and processes designed to minimise environmental harm. This concept can be very useful to both researchers and marketers interested in understanding how it affects consumers' responses to environmentally based marketing actions (Haws et al., 2014), including the response to green marketing communications (Bailey et al., 2016a).

\subsection{Green communication}

Traditionally manufacturers have communicated the environmentally friendly characteristics of their products to consumers through advertising. This has led to the growth of a significant segment of well-informed green consumers who exert pressure on producers with criticism about the type of communication delivered (Maniatis, 2016). However, this group is small in relation to the number of consumers who need to be influenced to adopt greener consumption and who represent a potential market. When consumers have a low interest in certain kinds of goods or are reluctant to adopt a certain behaviour recommended, from a marketing point of view, adopting specific and appropriate communication strategies when targeting these groups of individuals is vital. An important question to be considered is whether some consumers are more receptive to green communications than others; determining receptivity to green communication is important for the message (Bailey at al. (2016b) and could be a useful tool for companies that wish to target their communication efforts at individuals who may be more predisposed to green marketing. However, Zabkar and Hosta (2013) emphasise that although green marketing has been effective when the message is directed at consumers who are already concerned about the environment, further insights are needed about how to appeal to other consumers, including those who are more sceptical about environmental claims (Mohr et al., 1998).

According to Bailey at al. (2016b), consumers will react differently to environmental communication and appeals based on their levels of receptivity to green communication, specifically in the form of green advertising. The latter implies greater efforts on the part of the companies to "convince" the audience about the greenness of their arguments and the products/services offered. The issue is particularly significant in a context where consumers are now more cynical and sceptical of advertising in general, but to green and social messages, in particular. 
Shrum et al. (1995), in a much earlier study, noted that consumers interested in buying green products were sceptical regarding general advertising, and that despite females being more predisposed to buy responsibly, they believed that, sometimes, advertising offends their intelligence. This may have changed over time, however, a later study by D'Souza and Taghian (2005) found that even those consumers more environmentally concerned, do not consider advertisements, and green advertising in general, to be very convincing as there have been repeated false claims and exaggerations. Kilbourne (1995) suggested that overall, the credibility of green advertising is relatively low because of the vague/ambiguous arguments (without a clear meaning), omissions (essential information is omitted to assess its truthfulness), falsities (something that is fabricated/invented) or a combination of those identified above (Carlson et al., 1993). Furlow (2010) provides a very clear rationale for the scepticism and lack of credibility suggesting that to understand many of the environmental arguments communicated require a scientific background in environmental issues, given the complexity of the theme and the language used. Most consumers are unable to comprehend the messages delivered fully.

Nevertheless, some studies have indicated that green advertising and green marketing can have an influence on consumers' attitudes and intentions (Paço and Reis, 2012). For example, Chan (2000), in a study evaluating the influence of environmental claims on the success of environmental advertising, found that the image that individuals have of a certain claim affected their attitudes regarding the advertisement and the attitudes towards the brand, as well as their buying intentions. In turn, Bailey at al. (2016a), exploring the link between green consumption values and consumer response to green advertising found a positive relationship between the two constructs, that is, green consumption values influence consumer perceptions of the credibility of an entity transmitting green information.

\subsection{Buying Behaviour}

Green buying behaviour is generally associated with purchasing in a responsible, ethical, sustainable and environmentally friendly way. According to Paço et al. (2013), that behaviour includes buying energy efficient products, avoiding over packaged goods, exhibiting a preference for biodegradable and recycled articles, buying fair-trade and locally sourced products, contributing not only to equity and wellbeing in the community, but also to the reduction of pollution and the preservation of the planet. According to Kumar and Ghodeswar (2015), such purchasing decisions also take the form of supporting green companies, adopting 
sustainable consumption practices and being likely to spend more on green products. In fact, the literature exposes several different ways to measure environmentally friendly purchasing behaviour. Some researchers have focused more on the functional aspects of the products; others have adopted a more holistic approach to buying behaviour.

Studies show a range of expected behaviours that are typically associated with the green consumer (Laroche et al., 2001). It has been proposed that the more engaged consumers are with the environment, the more likely they are to acquire and use green products (Schuhwerk and Lefkokk-Hagius, 1995). Chan (1996) reported that individuals who were more concerned about conserving the environment tended to purchase more green products. It should be noted however, that despite the large numbers of consumers who voice concerns about environmental problems, it is also evident that concerns are only translated into actions if there are no hard "costs" involved, such as making a sacrifice in lifestyles (Laroche et al., 2002).

The relationship between environmental concern and behaviour is undoubtedly not clear-cut: studies from Moisander (2007) and Thøgersen (1999) suggest that consumers do not always base their buying decisions on their attitudes towards the environment. Although some customers are undoubtedly more cautious in their purchasing decisions, influenced by environmental concerns to the extent that they check such things as product composition, packaging, materials, etc. (Hasan et al., 2012). Those individuals, exemplifying a greener lifestyle, are crucial to companies and to other consumers, since they are serving by example (buying fair trade, recycling, saving energy, etc.) to contribute to the sustainability of the planet. Apart from individual motivation, Cherian and Jacob (2012) identify other relevant factors that influence consumers to buy environmentally friendly products including: the availability and validity of the information, the type of green communication and environmental claims used by industry and the assortment of green products presented by producers.

Contrary to Chan's (2001) study, in which individuals reported a high level of environmentally friendly purchase intention that actually had no impact on purchasing behaviour, other researchers (e.g. Akehurst et al., 2012; Schuhwerk and Lefkokk-Hagius, 1995) evidenced some linkage between intentions and buying of green products. 
Green behaviour is undoubtedly complex, attested by research results, which provide contradictory evidence. As referred, studies explore a range of different influences on purchasing from internal factors (such as attitudes, concern, values) social factors and external factors. In a recent literature review, Liobikiene and Bernatoniene (2017) highlight such complexities, reinforcing that concern in one aspect or area does not necessarily mean concern in others.

\section{Proposal of a New Model of Green Consumer Behaviour}

Green consumer behaviour modelling tends to be viewed by most researchers as a process ordered into a cognitive hierarchy consisting of values, attitudes/norms, intentions and behaviours (e.g. Homer and Kahle, 1988; Paul et al., 2016). Moreover, general value orientations influence attitudes regarding specific contexts, and attitudes, in turn, influence behaviours (Vaske and Donnelly 1999). Nevertheless, some research around the green attitude-behaviour link failed to return highly predictive relationships (Hini et al., 1995). These conflicting results could be attributed to the differences in constructs and measurements, which justify the need for further research focusing on the values-attitudesbehaviour hierarchy. Milfont et al. (2010) recommend the expansion of the prevailing models, as well as the need to test and compare samples from several countries.

Thus, based on the above literature review, an alternative conceptual model is proposed in Figure 1 to illustrate the hypothesised relationship among the constructs discussed previously. This research intends to present a valid proposal of a green consumer behaviour model in which the antecedents of green behaviour are General Prosocial Attitudes (lasting dispositional tendency for an individual to think about the rights and well-being of others, to feel empathy and worry for others), Green Consumption Values, and Receptivity to Green Advertising. It is suggested that General Prosocial Attitudes will contribute to Green Consumption Values (tendency to explore the value of environmental protection through one's purchases and consumption behaviours), which in turn will contribute to Receptivity to Green Communication (attention given or feelings towards green advertising) and Buying Behaviour; and also that to Receptivity to Green Communication will result on positive Buying Behaviour. 
Figure 1 - Proposal of a new model of green consumer behaviour

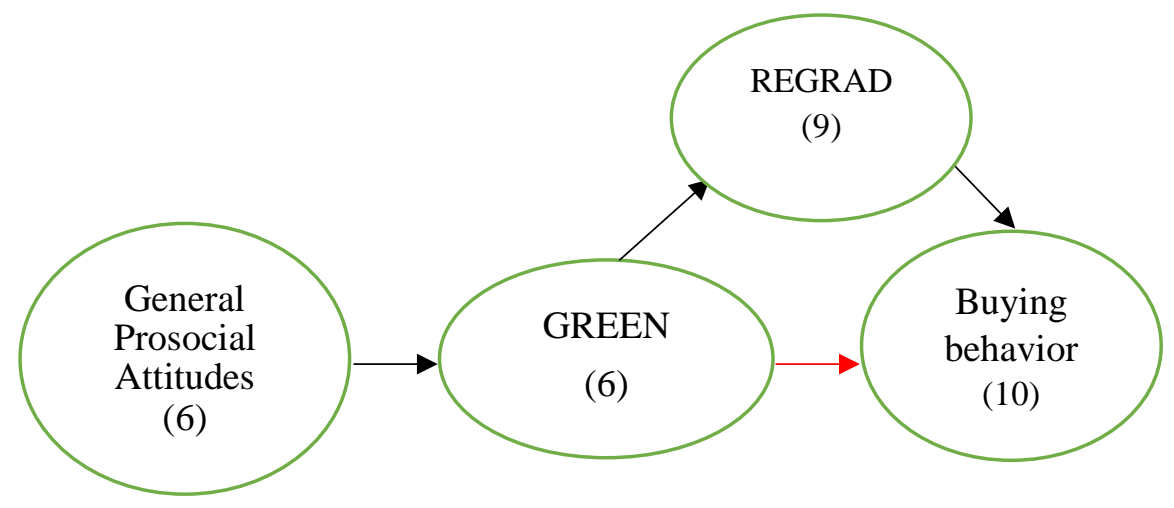

Given the model represented above, the following hypotheses were formulated

$\mathbf{H}_{1}$ : General Prosocial Attitudes (GPA) positively affects individuals' Green consumption values (GREEN).

$\mathbf{H}_{2}$ : Green consumption values (GREEN) positively affect individuals' receptivity to green communication (REGRAD)

$\mathbf{H}_{3}$ : Green consumption values (GREEN) positively affect individuals' Buying Behaviour (BB).

$\mathbf{H}_{4}$ : Receptivity to green communication (REGRAD) positively affects individuals' Buying Behaviour (BB).

\section{Method}

\subsection{Questionnaire Design and Variable Measurement}

A survey approach was used to test the proposed model. The method of data collection was a survey, taking the form of a self-administered questionnaire (see the list of variables in the Appendix), consisting mainly of closed questions, covering three main sections: (i) opinion questions (prosocial attitudes, green values and receptivity to green communications); (ii) frequency questions (buying behaviour); and (iii) demographics (age, gender, level of education, nationality).

The research used already tested scales. The novelty is that at this time they were used in an integrated way in order to test a model and measure certain behaviours. The respondents were asked to mark their opinion using a seven points scale varying from $7=$ totally agree to $1=$ 
totally disagree; in the case of the Buying Behaviour construct, individuals were asked to point their level of frequency using a seven points scale ranging from $7=$ always to $1=$ never.

The questionnaire was pretested by a group of 24 individuals in order to identify language and understanding problems.

The six statements to measure General Prosocial Attitudes (GPA) were adapted from Osgood and Muraven (2015) because of their capacity to measure altruistic behaviours usually associated to environmental concern. Zabkar and Hosta (2013) have also used this scale arguing that the difference between intention and green consumption could be addressed by prosocial status perceptions.

The tendency to explore the value of environmental protection through individual buying and consumption behaviours is explained by the Haws et al. (2014) GREEN scale. This instrument predicts consumer preference for environmentally friendly products and indicates that stronger green consumption values increase preference for environmentally friendly products through more favourable evaluations of the non-environmental attributes of these products. The six-item scale GREEN was also used recently by Bailey et al. (2016 a, b).

The receptivity to green advertising (REGRAD), understood as the extent to which consumers pay attention and are favourably inclined and attentive to advertising that uses green messages to promote products or the company itself, is measured by a nine items scale (Bailey at al., 2016b).

To access Buying Behaviour, ten items of the 'Ecologically Conscious Consumer Behaviour' (ECCB) scale of Straughan and Roberts (1999) were used, covering topics such as the package, energy-efficiency, polluting or recycled products. This scale has already been tested and included in consumer behaviour models by Paço et al. $(2013,2014)$.

After collection, the data was statistically analysed and interpreted using the statistical software PLS 3.0. Structural Equation Modelling (SEM) was used to analyse the data. 


\subsection{Research sample}

Responses were sought from two countries: England and Portugal. The two countries were selected for convenience (the authors' countries of residence) but also to enable comparisons to be made at a later point as part of an extended study to compare across different economic, social and cultural settings in relation to environmental issues. Portugal, contrasts with England in that is less developed. Portugal has been slower to engage with environmental issues than would seem to be the case in England. England, in contrast was an early engager with sustainable development issues and environmental management. European Commission (2014), by means of the Special Eurobarometer 416 evidences the differences between the two countries (reinforcing the very different realities of England and Portugal. The data shows that while both English (94\%) and Portuguese (97\%) respondents believe that protecting the environment is important, and agree that environmental issues have a direct effect on their daily life (PT $-86 \%$ and $\mathrm{UK}-78 \%$ ) there are differences between the two countries in relation to behaviours on a number of measures. Thus, for example, the Portuguese are less likely to reduce waste and be concerned about over packaging (PT $-18 \%$ and UK $-40 \%$ ). Similarly, they are less likely to buy environmentally friendly products, be concerned about car use and buying local goods. Very few consumers in Portugal would be willing to buy environmentally friendly products if prices were higher. In this regard, Portugal came at the end of the rankings whereas English citizens were ranked above the mean.

The questionnaire was first developed in English and then to gather data from Portugal was translated using standard back-translation protocol. Small adjustments had to be made so that the questions could be understood by respondents. The questionnaire was made available electronically using Survey Monkey. Data was collected on the platform over a two-month period during which anyone completing the questionnaire could pass on the survey link to others. 471 questionnaires were collected (240 from PT and 231 from UK).

The sample in this study is composed by 471 individuals. The majority of the respondents are females $(67.52 \%)$. Are aged between 18 and 85 years old, quite equality distributed among the age groups (the group with less persons is the one of 26-35 years old with $13.16 \%$ ). The majority of the respondents (69\%) have high levels of education, being this percentage a bit higher in the UK sample. Although by country the sample reveals slightly differences, in this research, the sample was used as a global one. Table 1 shows the sample characteristics. 
Table 1 - Sample composition

\begin{tabular}{|c|c|c|c|c|c|c|}
\hline Age & Portugal & \% & UK & \% & Total & \% \\
\hline $15-25$ & 72 & $30.00 \%$ & 31 & $13.42 \%$ & 103 & $21.87 \%$ \\
\hline $26-35$ & 35 & $14.58 \%$ & 27 & $11.69 \%$ & 62 & $13.16 \%$ \\
\hline $36-45$ & 59 & $24.58 \%$ & 49 & $21.21 \%$ & 108 & $22.93 \%$ \\
\hline $46-55$ & 38 & $15.83 \%$ & 66 & $28.57 \%$ & 104 & $22.08 \%$ \\
\hline $56-65$ & 14 & $5.83 \%$ & 33 & $14.29 \%$ & 47 & $9.98 \%$ \\
\hline $66-75$ & 6 & $2.50 \%$ & 19 & $8.23 \%$ & 25 & $5.31 \%$ \\
\hline $76-85$ & 0 & $0.00 \%$ & 4 & $1.73 \%$ & 4 & $0.85 \%$ \\
\hline Missing & 16 & $6.67 \%$ & 2 & $0.87 \%$ & 18 & $3.82 \%$ \\
\hline Total & 240 & $100,00 \%$ & 231 & $100,00 \%$ & 471 & $100,00 \%$ \\
\hline Gender & Portugal & $\mathbf{\%}$ & UK & $\%$ & Total & \% \\
\hline Male & 88 & $:$ & 62 & $26.84 \%$ & 150 & $31.85 \%$ \\
\hline Female & 150 & $62.50 \%$ & 168 & $72.73 \%$ & 318 & $67.52 \%$ \\
\hline Missing & 2 & $0.83 \%$ & 1 & $0.43 \%$ & 3 & $0.64 \%$ \\
\hline Total & 240 & $100.00 \%$ & 231 & $100.00 \%$ & 471 & $100.00 \%$ \\
\hline School Level & Portugal & $\mathbf{\%}$ & UK & $\mathbf{\%}$ & Total & $\%$ \\
\hline Graduate & 141 & $58.75 \%$ & 184 & $79.65 \%$ & 325 & $69.00 \%$ \\
\hline Secondary & 76 & $31.67 \%$ & 26 & $11.26 \%$ & 102 & $21.66 \%$ \\
\hline Elementary & 20 & $8.33 \%$ & 20 & $8.66 \%$ & 40 & $8.49 \%$ \\
\hline Missing & 3 & $1.25 \%$ & 1 & $0.43 \%$ & 4 & $0.85 \%$ \\
\hline Total & 240 & $100.00 \%$ & 231 & $100.00 \%$ & 471 & $100.00 \%$ \\
\hline
\end{tabular}

\section{Results: presentation and discussion}

The model test was carried out in two different analytical phases according to the recommendations set out by Chin (1998a; 1998b) and Hair, Ringle and Sarstedt (2011). Firstly, the measurement model was analysed, in order to verify whether the indicators for each construct were valid and robust for measuring the respective analytical constructs. This involves calculating: a) the composite reliability of each indicator's loadings; b) the average variance extracted (AVE), and c) the discriminant validity of the reflective constructs.

Table 2 presents the results for composite reliability, Cronbach's Alpha and AVE, after eliminating variables $\mathrm{BB} 1$ and $\mathrm{BB} 2$, for not conforming to the required minimum, as recommend by Bagozzi and Yi (1998). 
Table 2 - Composite reliability, Cronbach's Alpha and AVE

\begin{tabular}{|c|c|c|c|c|c|c|c|}
\hline CONSTRUCT & Indicator & Value & t Statistics & p Values & \begin{tabular}{|l|} 
Composite \\
Reliability
\end{tabular} & Alpha & AVE \\
\hline \multirow{7}{*}{ BB } & BB3 & 0.809 & 42.028 & 0.000 & \multirow{7}{*}{0.94} & \multirow{7}{*}{0.92} & \multirow{7}{*}{0.68} \\
\hline & BB4 & 0.870 & 56.856 & 0.000 & & & \\
\hline & BB5 & 0.864 & 55.034 & 0.000 & & & \\
\hline & BB6 & 0.796 & 33.983 & 0.000 & & & \\
\hline & BB7 & 0.746 & 30.584 & 0.000 & & & \\
\hline & BB8 & 0.832 & 42.794 & 0.000 & & & \\
\hline & BB9 & 0.863 & 57.825 & 0.000 & & & \\
\hline \multirow{6}{*}{ GPA } & GPA1 & 0.774 & 13.319 & 0.000 & \multirow{6}{*}{0.93} & \multirow{6}{*}{0.91} & \multirow{6}{*}{0.73} \\
\hline & GPA2 & 0.815 & 14.679 & 0.000 & & & \\
\hline & GPA3 & 0.880 & 32.842 & 0.000 & & & \\
\hline & GPA4 & 0.931 & 106.236 & 0.000 & & & \\
\hline & GPA5 & 0.857 & 26.721 & 0.000 & & & \\
\hline & GPA6 & 0.774 & 13.319 & 0.000 & & & \\
\hline \multirow{6}{*}{ GRE } & GRE1 & 0.807 & 40.319 & 0.000 & \multirow{6}{*}{0.94} & \multirow{6}{*}{0.92} & \multirow{6}{*}{0.72} \\
\hline & GRE2 & 0.855 & 39.208 & 0.000 & & & \\
\hline & GRE3 & 0.883 & 50.157 & 0.000 & & & \\
\hline & GRE4 & 0.840 & 53.665 & 0.000 & & & \\
\hline & GRE5 & 0.866 & 66.063 & 0.000 & & & \\
\hline & GRE6 & 0.835 & 35.581 & 0.000 & & & \\
\hline \multirow{9}{*}{ REG } & REG1 & 0.869 & 50.944 & 0.000 & \multirow{9}{*}{0.96} & \multirow{9}{*}{0.95} & \multirow{9}{*}{0.73} \\
\hline & REG2 & 0.756 & 28.488 & 0.000 & & & \\
\hline & REG3 & 0.867 & 45.571 & 0.000 & & & \\
\hline & REG4 & 0.909 & 74.164 & 0.000 & & & \\
\hline & REG5 & 0.911 & 54.725 & 0.000 & & & \\
\hline & REG6 & 0.839 & 36.505 & 0.000 & & & \\
\hline & REG7 & 0.752 & 23.034 & 0.000 & & & \\
\hline & REG8 & 0.860 & 55.862 & 0.000 & & & \\
\hline & REG9 & 0.916 & 105.922 & 0.000 & & & \\
\hline
\end{tabular}

As may be observed from table 2, all the constructs loadings return results in excess of 0.7 and hence in keeping with the recommendations from Hair et al. (1998). This means that all indicators are adequate to measure the construct they belong to and thus sufficient in its representations of the inherent constructs. Table 2 also show the reliability for all construct is good as the results for composite reliability and Cronbach's alpha return values above 0.7 as recommend by Bagozzi and Yi (1998). The average extracted variance (AVE) also presents values better than 0.5 as recommended by Bagozzi and Yi (1998) meaning that all constructs capture more that $50 \%$ of the variance.

The next step is to examine the discriminant validity of the constructs (table 3). 
Table 3 - Discriminant validity

\begin{tabular}{|l|r|r|r|r|}
\hline \multicolumn{1}{|c|}{ CONSTRUCTS } & \multicolumn{1}{c|}{ BB } & \multicolumn{1}{c|}{ GPA } & \multicolumn{1}{c|}{ GREEN } & REGRAD \\
\hline BB & $\mathbf{0 . 8 2 7}$ & & & \\
\hline GPA & 0.250 & $\mathbf{0 . 8 5 3}$ & & \\
\hline GREEN & 0.739 & 0.324 & $\mathbf{0 . 8 4 8}$ & \\
\hline REGRAD & 0.564 & 0.404 & 0.675 & $\mathbf{0 . 8 5 5}$ \\
\hline
\end{tabular}

Note: Square Root of AVE in diagonals

Table 3 sets out how discriminant validity is achieved. As observed, the square root of the average variance extracted all constructs return results higher than the correlation between the constructs as recommended by Fornell and Laker (1981), and thus showing that the observed variables correlate more highly with the variables inside the parent construct than with the variables outside the parent construct. Furthermore, no construct reports loadings greater than those returned by the construct itself (Chin, 1998b).

After validating the measurement model, we proceeded with testing the structural model, its explicative capacity $\left(\mathrm{R}^{2}\right)$ and the statistical significance of the diverse structural coefficients (Hair el al., 1998). The model presents an $\mathrm{R}^{2}$ of $55 \%$, which is the variance explained by all constructs on Buying Behaviour (BB). Table 4 shows the path coefficients and its statistical significance.

Table 4 - Path coefficients and statistical significance

\begin{tabular}{|r|c|c|c|}
\hline $\begin{array}{c}\text { Relations between } \\
\text { Constructs }\end{array}$ & Value & t Statistics & p Values \\
\hline GPA $->$ GREEN & 0.324 & 6.950 & 0.000 \\
\hline GREEN -> REGRAD & 0.675 & 24.303 & 0.000 \\
\hline GREEN -> BB & 0.659 & 15.799 & 0.000 \\
\hline REGRAD -> BB & 0.118 & 2.092 & 0.037 \\
\hline
\end{tabular}

As can be observed on table 4, all paths are significant. GPA has an influence on GREEN of 0.32 , which means that if GPA raises by one point, GREEN will raise by 0.32 points. The greater influence is of GREEN on REGRAD (0.675) and GREEN has an influence of 0.659 on BB. The influence of REGRAD on BB turned out being statically significant, but above the minimum value (0.2) considered relevant by Chin (1998a; 1998b).

Figure 2 shows the final model and its paths. 
Figure 2 - Final model

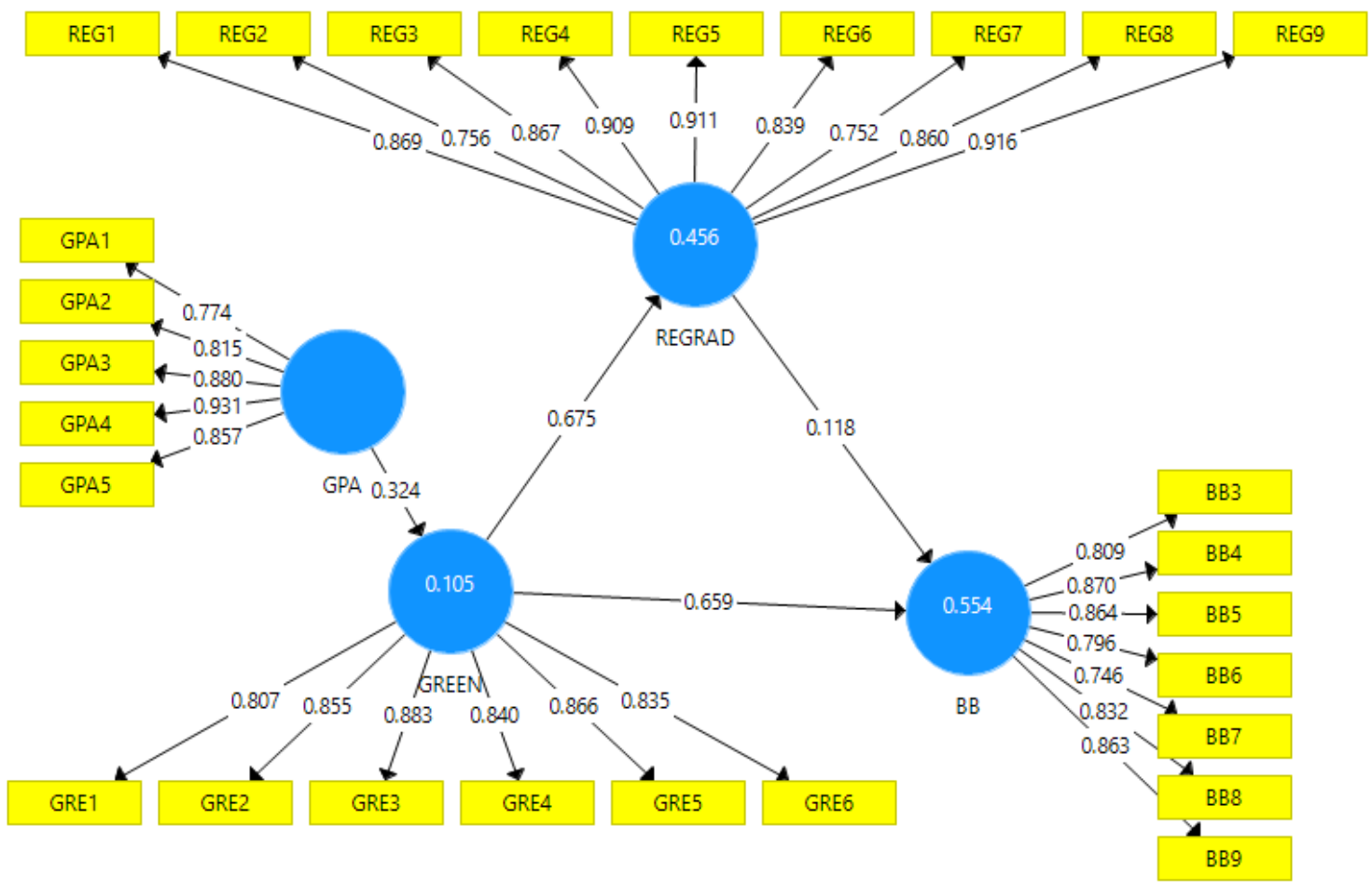

As observed in figure 2, general prosocial attitudes, which are related with doing good for the benefits of others, is positively related to the existence of green values, therefore, it is possible to say that people who care for others and societal wellbeing have higher green values. It is thus possible to confirm the first hypothesis $H_{1}$ : General Prosocial Attitudes (GPA) positively affects individuals' Green consumption values (GREEN). These results confirm the results of Zabkar and Hosta (2013), but are contrary to the ones of Osgood and Muraven (2015).

In turn, possessing higher green values (valuing the environment), predisposes consumers to be more receptive to green advertising appeals, which allows for confirmation of $\mathrm{H}_{2}$ : Green consumption values (GREEN) positively affects individuals' receptivity to green communication (REGRAD). This result is highly supported by the path value of 0.675 , and is in line with the results of Bailey et al. (2016a). Additionally, green consumption values (GREEN) also positively affect individuals' buying behaviour (BB) (0.659) as stated in $H_{3 \text { : }}$ Green consumption values (GREEN) positively affect individuals' Buying Behaviour (BB), which is in line with Haws et al. (2014) results reporting that consumers with stronger green consumption values are usually more oriented towards buying in a responsible way respecting the natural environment. 
Although the results show significance for the statistical tests of $H_{4}$ : Receptivity to green communication (REGRAD) positively affects individuals' Buying Behaviour (BB), the influence of green communication on buying behaviour cannot be considered relevant.

\section{Conclusion}

This research sought to develop further understanding and to extend the debate within the literature on the various factors that influence green buying behaviour. The results indicate the importance of taking into consideration consumer green values and prosocial behaviour to explain the predisposition to accept green marketing communications appeals and exhibit green buying behaviour.

The research contributes to theory by providing further insights on the factors that influence green buying behaviour and particularly the importance of prosocial attitudes. While prosocial status has already been tested with contradictory results, general prosocial attitudes are seen to have a direct influence on green consumption values. At the same time, the impact of green values is seen to have a positive influence on receptivity to green communication and buying behaviour.

The findings of this research will also be relevant to producers and professionals dealing with green products, particularly marketers. With regard to the latter, some consumers will exhibit the traits and attitudes considered in this research (prosocial values for example); marketing campaigns should take into account all the factors influencing buying behaviour in order to target the market and by designing communication likely to have the greatest appeal.

This study has some limitations, namely, that the sample is not completely random and the survey was conducted on-line, therefore excluding some members of the population who do not have internet access. Further, the use of two countries is something that reinforces the results, but is also a limitation, as having used other countries with others habits and values might have led to different results; some caution is thus advised with regard to generalization from the results. Future research should consider testing this model and evaluating its applicability in different countries. There is also the potential for some constructs to vary 
across cultures, which may suggest adaptations of the used scales based on cultural differences.

\section{Appendix}

\begin{tabular}{ll}
\hline \multicolumn{1}{c}{ General Prosocial Attitudes } \\
\hline GPA1 & It is important that others are happy \\
GPA2 & It is important to help someone who needs it \\
GPA3 & I want to help others \\
GPA4 & The well-being of others is important \\
GPA5 & The needs of others are important \\
GPA6 & It is important that all people are happy
\end{tabular}

\section{Green consumption values}

GRE1 It is important to me that the products I use do not harm the environment

GRE2 I consider the potential environmental impact of my actions when making many of my decisions

GRE3 My purchase habits are affected by my concern for our environment

GRE4 I am concerned about wasting the resources of our planet

GRE5 I would describe myself as environmentally responsible

GRE6 I am willing to be inconvenienced in order to take actions that are more environmentally friendly

\begin{tabular}{ll}
\hline & \multicolumn{1}{c}{ Receptivity to green communication } \\
\hline REG1 & I support brands that support the environment. \\
REG2 & I tend to pay attention to advertising messages that talk about the environment. \\
REG3 & The use of green messages in ads affects my attitude toward the ads. \\
REG4 & I respond favorably to brands that use green messages in their advertising. \\
REG5 & I am the kind of consumer who responds favorably when brands use green messages in their ads. \\
REG6 & I think that green advertising is valuable. \\
REG7 & Green advertising is a necessary form of advertising. \\
REG8 & I am the kind of consumer who is willing to purchase products marketed as being green. \\
REG9 & I tend to pay attention to green advertising messages. \\
\hline & \\
\hline BB1 & I try to buy energy efficient products and appliances \\
BB2 & I avoid buying products that have excessive packaging \\
BB3 & When there is a choice, I choose the product that causes the least pollution \\
BB4 & I have switched products/brands for ecological reasons \\
BB5 & I make every effort to buy paper products made from recycled paper \\
BB6 & I use environmentally friendly soaps and detergents \\
BB7 & I have convinced members of my family or friends not to buy some products which are harmful to \\
the environment \\
BB8 & Whenever possible, I buy products packaged in reusable containers \\
BB9 & I try to buy products that can be recycled \\
BB10 & I buy high efficiency light bulbs to save energy \\
\hline
\end{tabular}




\section{Acknowledgments}

This work is financed by National Funds through the FCT Foundation for Science and Technology - Project UID/GES/04630/2013.

\section{References}

Ajzen, I., 1991. The Theory of Planned Behavior. Organ. Behav. Hum. Decis. 50(2), 179211.

Akehurst, G., Afonso, C., Gonçalves. H., 2012. Re-examining green purchase behaviour and the green consumer profile: new evidences. Manage. Decis. 50(5), 972-988.

Antil, J.H., 1984. Socially responsible consumers: Profile and implications for public policy. J. Macromarketing. 5(2), 18-39.

Bagozzi, R.P., Yi, Y., 1988. On the evaluation of structural equation models. J. Acad. Mark. Sci. 1, 74-94.

Bailey, A., Mishra, A., Tiamiyu M., 2016a. GREEN consumption values and Indian consumers' response to marketing communications. J. Consum. Mark. 3(7), 562-573.

Bailey, A., Mishra, A., Tiamiyu, M., 2016b. Green advertising receptivity: An initial scale development process. J. Mark. Communications. 22(3), 327-345.

Biswas, A., 2017. A consumption value-gap analysis for sustainable consumption. Environ Sci Pollut Res. 24, 7714-7725.

Carlson, L., Grove, S.J., Kangun, N., 1993. A content analysis of environmental advertising claims: a matrix method approach. J. Advertising. 22(3), 27-39.

Cerri, J., Testa, F., Rizzi, F., 2018. The more I care, the less I will listen to you: How information, environmental concern and ethical production influence consumers' attitudes and the purchasing of sustainable products. J. Clean. Prod. 175, 343-353.

Chan, R., 2001. Determinants of Chinese consumers' green purchase behaviour. Psychol. Market. 18(4): 389-413.

Chan, R.K., 2000. The effectiveness of environmental advertising: the role of claim type and the source country green image. Int. J. Advertising. 19(3), 349-375.

Chan, T., 1996. Concerns for environmental issues and consumer purchase preferences: a two-country study. J. Int. Consum. Mark. 9(1), 43-55.

Cherian J, Jacob J., 2012. Green marketing: a study of consumers' attitude towards environment friendly products. Asian Soc. Sci. 8(12), 117-126.

Chin, W. 1998a. Issues and Opinion on Structural Equation Modelling. Manag. Inf. Syst. Q. 22(1), 7-15.

Chin, W.W. 1998b. The partial least squares approach to structural equation modelling, in Marcoulides, G.A. (Ed.), Modern Methods for Business Research, pp. 295-336, Lawrence Erlbaum Associates, Mahwah, New Jersey. 
Cropanzano, R., Mitchell, M.S. 2005. Social exchange theory: an interdisciplinary review. J. Manag. 31, 874-900.

D'Souza, C., Taghian, M., 2005. Green advertising effects on attitude and choice of advertising themes. Asia Pacific J. Mark. Logist. 17(3), 51-66.

European Commission, 2014. Special Eurobarometer 416 Attitudes of European citizens towards the environment.

http://ec.europa.eu/commfrontoffice/publicopinion/archives/ebs/ebs 416_en.pdf. Accessed at 14/07/17.

Fishbein, M., Ajzen, I., 1975. Beliefs, attitude, intention and behavior: An Introduction to Theory and Research. Addison-Wesley, Reading, MA.

Fornell, C., Laker, D.F., 1981. Evaluating structural equations models with unobservable variables and measurement error. J. Mark. Res. 18(1), 39-50.

Furlow, E., N. 2010. Greenwashing in the new millennium. J. Appl. Bus. Econ. 10(6), 22-26.

Hair, J., Anderson, R., Tatham, R., Black, W. 1998. Multivariate Data Analysis, $5^{\text {th }}$ ed., Prentice-Hall, New Jersey.

Hair, J.F., Ringle, C.M., Sarstedt, M., 2011. PLS-SEM: Indeed a Silver Bullet. J. Mark. Theory Pract. 19 (2), 139-52.

Hasan, S., Subhani, M., Osman, A., 2012. The crux of green marketing: an empirical effusive study. Eur. J. Soc. Sci. 27(3), 425-435.

Haws, K.L., Bearden, W.O., Nenkov, G.Y., 2012. Consumer spending self-control effectiveness and outcome elaboration prompts. J. Acad. Market Sci. 40(5), 695-710.

Haws, K.L., Winterich, K.P., Naylor, R.W., 2014. Seeing the world through GREEN-tinted glasses: green consumption values and responses to environmentally friendly products. J. Consumer Psychol. 24(3), 336-354.

He, A., Cai, T., Deng, T., Li, X., 2016. Factors affecting non-green consumer behaviour: an exploratory study among Chinese consumers. Int. J. Consum. Stud. 40, 345-356.

Herbes, C. Beuthner, C., Ramme, I. 2018. Consumer attitudes towards biobased packaging A cross-cultural comparative study. J. Clean. Prod. 194, 203-218.

Hini, D., Gendall, P. and Kearns, Z., 1995. The link between environmental attitudes and behaviour. Marketing Bull. 6, 22-31.

Homer, P.M., Kahle, L.R., 1988. A structural equation test of value-attitude-behaviour hierarchy. J. Pers. Soc. Psychol. 54(4), 638-646.

Huttunen, K., Autio, M., 2010. Consumer enthuses in finish consumer life stories agrarianism, economism and green consumerism. Int. J. Consum. Stud. 34, 146-152.

Kilbourne, W.E., 1995. Green advertising: salvation or oxymoron. J. Advertising. 24(2), 7-19. 
Kumar, P., Ghodeswar, B., 2015. Factors affecting consumers' green product purchase decisions. Market. Intell. Plann. 33(3), 330-347.

Kuo, T.C., Tseng, M.L., Lin, C.H., Wang, R.W., Lee, C.H., 2018. Identifying sustainable behavior of energy consumers as a driver of design solutions: The missing link in eco-design. J. Clean. Prod. 192, 486-495,

Laroche, M., Tomiuk, M., Bergeron, J., Barbaro-Forleo, G., 2002. Cultural differences in environmental knowledge, attitudes, and behaviors of Canadian consumers. Can. J. Adm. Sci. 19(3), 267-283.

Lastovicka, J.L., Bettencourt, L.A., Hughner, R.S., Kuntze, R.J., 1999. Lifestyle of the tight and frugal: Theory and measurement. J. Consumer Res. 26(1), 85-98.

Lee, K., 2008. Opportunities for green marketing: young consumers. Market. Intell. Plann. 26(6), 573-586.

Lee, K., 2009. Gender differences in Hong Kong adolescent consumers' green purchasing behaviour. J. Consumer Mark. 26(2), 87-96.

Lichtenstein, D.R., Ridgway, N.M., Netemeyer, R.G., 1993. Price perceptions and consumer shopping behavior: A field study. J. Mark. Res. 234-245.

Liobikiene, G., Bernatoniene, J., 2017. Why determinants of green purchase cannot be treated equally? The case of green cosmetics: literature review. J. Clean. Prod. 162, 109-120.

Liu, W., Oosterveer, P., Spaargaren, G. 2016. Promoting sustainable consumption in China: a conceptual framework and research review. J. Clean. Prod. 134, Part A, 13-21.

Loundsbury, J., Tournatsky, L., 1977. A scale for assessing attitudes toward environmental quality. J. Soc. Psychol. 101, 299-305.

Maloney, M., Ward, M., 1973. Ecology: let's hear from the people - an objective scale for the measurement of ecological attitudes and knowledge. Am. Psychol. 28, 583-586.

Maniatis, P., 2016. Investigating factors influencing consumer decision-making while choosing green products. J. Clean. Prod. 132, 215-228.

Milfont, T. L., Duckitt, J., Wagner, C., 2010. A cross-cultural test of the value-attitudebehaviour hierarchy. J. Appl. Social Psych. 40(11), 2791-2813.

Mohr, L.A., Eroglu, D., Ellen, P.S., 1998. The development and testing of a measure of skepticism toward environmental claims in marketers' communications. J. Consum. Aff. 32(1), 30-55.

Moisander, J., 2007. Motivational complexity of green consumerism. Intern. J. Consum. Studies. 31(4), 404-409.

Osgood, J.M., Muraven, M., 2015. Self-control depletion does not diminish attitudes about being prosocial but does diminish prosocial behaviors. Basic Appl. Soc. Psych. 37, 68-80. 
Paço, A., Alves, H., Shiel, C., Leal Filho, W., 2013. Development of a green consumer behavior model. Int. J. Consum. Stud. 37, 414-429.

Paço, A., Alves, H., Shiel, C., Leal Filho, W., 2014. An analysis of the measurement of the construct "buying behaviour" in green marketing. J. Integr. Environ. Sci. 11(1), 55-69.

Paço, A., Raposo, M., 2010. Green consumer market segmentation: empirical findings from Portugal. Int. J. Consum. Stud. 4, 429-436.

Paço, A., Reis, R., 2012. Factors affecting skepticism toward green advertising. J. Advertising. 41(4), 147-155.

Paul, J., Modi, A., Patel, J., 2016. Predicting green product consumption using theory of planned behavior and reasoned action. J. Retailing Cons. Serv. 29, 123-134.

Pickett, G.M., Kangun N., Grove S.J, 1955. An examination of the conservative consumer: implications for public formation policy in promoting conservation behaviour, in: Polonsky M.J., Mintu-Wimsatt A.T. (Eds.), Environmental Marketing: Strategies, Practice, Theory and Research, The Haworth Press, New York, pp. 77-99.

Rahnama, H., Rajabpour, S., 2017. Identifying effective factors on consumers' choice behavior toward green products: the case of Tehran, the capital of Iran. Environ Sci Pollut R. $24(1), 911-925$.

Rex, E., Baumann, H., 2007. Beyond ecolabels: what green marketing can learn from conventional marketing. J. Clean. Prod. 15, 567-576.

Schlegelmilch, B., Bohlen, G., Diamantopoulos, A. 1996. The link between green purchasing decisions and measures of environmental consciousness, Eur. J. Marketing. 30(5), 35-55.

Schuhwerk, M., Lefkokk-Hagius, R., 1995. Green or not-green? Does type of appeal matter when advertising a green product? J. Advertising. 24, 45-55.

Sheth, J., Newman B., Gross, B., 1991. Why we buy what we buy: a theory of consumption values. J. Bus. Res. 22(2), 159-170.

Sheth, J.N., Sethia, N.K., Srinivas, S., 2011. Mindful consumption: A customer centric approach to sustainability. J. Acad. Market Sci. 39(1), 21-39.

Shi, L., 2002. An empirical study on green consumption attitudes and behavior of Chinese consumers. J. Consump. Econ. 18, 39-42.

Shrum, L.J., McCarty, J.A., Lowrey, T.M., 1995. Buyer characteristics of green consumer and their implications for advertising strategy. J. Advertising. 24(2), 71-82.

Snippe, E., Jeronimus B.F., Aan Het Rot, M., Bos, E.H., de Jonge, P., Wichers, M., 2017. The reciprocity of prosocial behavior and positive affect in daily life. J Pers. 86(2):139-146.

Steele, W.R., Schreiber, G.B., Guiltinan, A., Nass, A., Glynn, S., Wright, D., Kessler, D., Schlumpf, K., Tu, Y., Smith, J.W., Garratty, G. 2008 The role of altruistic behavior, empathetic concern, and social responsibility motivation in blood donation behavior. Tranfusion, 48, 43-54. 
Straughan, R., Roberts, J., 1999. Environmental segmentation alternatives: a look at green consumer behaviour in the new millennium. J. Consum. Mark. 16(6), 558-575.

Thøgersen, J., 1999. The ethical consumer. Moral norms and packaging choice. J. Consum. Policy. 22(4), 439-460.

Tripathi, A., Singh, M., 2016. Determinants of sustainable/green consumption: a review. Int. J. Environ. Tech. Manag. 19(3/4), 316- 358.

Vaske, J.J., Donnelly, M.P., 1999. A Value-Attitude-Behavior model predicting wildland preservation voting intentions. Soc. Nat. Resources Int. J. 12(6), 523-537.

Weinstein, N., Ryan, R.M., 2013. When helping helps: autonomous motivation for prosocial behavior and its influence on well-being for the helper and recipient. J Pers Soc Psychol. 98(2), 222-244.

Welte, T., Anastasio, P., 2010. To conserve or not to conserve: is status the question? Environ. Behav. 42, 845.

Zabkar, V., Hosta, M., 2013. Willingness to act and environmentally conscious consumer behaviour: can prosocial status perceptions help overcome the gap? Int. J. Consum. Stud. 37 , 257-264. 